\title{
STUDI KARAKTERISTIK FISIK DAN MEKANIK EDIBLE FILM PATI UBI JALAR UNGU DENGAN PENAMBAHAN KITOSAN
}

\author{
STUDY OF PHYSICAL AND MECHANICS CHARACTERISTICS PURPLE SWEET POTATO \\ STARCH BASED EDIBLE FILM WITH CHITOSAN
}

\author{
Dhita Ekariski, Basito, Bara Yudhistira \\ Program Studi Teknologi Pangan, Fakultas Pertanian, Universitas Sebelas Maret Surakarta \\ email: dhita.eka.riski@gmail.com
}

Diserahkan [4 Juni 2017]; Diterima [8 Juli 2017]; Dipublikasi [31 Agustus 2017]

\begin{abstract}
Edible film is one of alternative packaging which can consume and still protect product from losing nutrition, appearance, flavor, dehydrate and deteriorate at storage and isn't damage environment. More research using local starch from sweet potato (Ipomea batatas L. poir) was studied. But, characteristic from sweet potato starch shows poor in quality. So, mixing starch with chitosan studied to make characteristic of edible film more useable for wide area. This research to know how is characteristic of edible film starchchitosan. One edible film use 0,8 $\mathrm{mL}$ glycerol or $20 \%(\mathrm{v} / \mathrm{w})$ and chitosan's soluble $1 \%$ acetate acid. One factor uses in this research is amount of chitosan with 3 level 0,5 gram; 1,0 gram; and 1,5 gram. Then, edible film analyzed physical (thickness, solubility and permeability) and mechanic (tensile strength and elongation). Result of research show more chitosan add significantly increased thickness and tensile strength of edible film and significantly decrease solubility and elongation of edible film. But, edible film show no significantly decrease of permeability. Adding more chitosan in edible film starch-glycerol increase edible film thickness to 0,13 -1,90 mm and decrease solubility to 66,87-58,20\%. Tensile strength show increase to 1,27-6,90 MPa and elongation decrease to 79,71-46,98\%. And for permeability of edible film decrease to $12,40-9,97\left(\mathrm{~g} / \mathrm{hour} \mathrm{m}^{2}\right)$.
\end{abstract}

Keyword: Chitosan, Edible film, Sweet Potato Starch

\section{ABSTRAK}

Edible film merupakan salah satu kemasan alternatif yang dapat dikonsumsi dan masih melindungi produk dari kehilangan nutrisi, penampilan, rasa, dehidrasi dan kerusakan selama penyimpanan serta tidak merusak lingkungan. Penelitian lebih lanjut menggunakan pati lokal dari ubi jalar (Ipomea batatas L. poir) telah dilakukan. Namun, karakteristik dari pati ubi jalar menunjukkan kualitas yang buruk. Jadi, pencampuran pati dengan kitosan untuk membuat karakteristik edible film lebih dapat digunakan untuk area yang luas. Penelitian ini untuk mengetahui bagaimana karakteristik edible film starch-chitosan. Perlakuan menggunakan $0,8 \mathrm{~mL}$ gliserol atau $20 \%$ (v / w) dan asam asetat $1 \%$ yang larut kitosan. Salah satu faktor yang digunakan dalam penelitian ini adalah jumlah kitosan dengan 3 level 0,5 gram; 1,0 gram; dan 1,5 gram. Kemudian, edible film dianalisis secara fisik (ketebalan, kelarutan dan permeabilitas) dan mekanik (kekuatan tarik dan perpanjangan). Hasil penelitian menunjukkan lebih banyak kitosan menambah secara signifikan peningkatan ketebalan dan kekuatan tarik edible film dan secara signifikan mengurangi kelarutan dan perpanjangan edible film. Namun, edible film tidak menunjukkan penurunan permeabilitas yang signifikan. Menambahkan lebih banyak kitosan dalam edible film starch-gliserol meningkatkan ketebalan film yang dapat dimakan menjadi 0,13-1,90 mm dan menurunkan kelarutan menjadi 66,87-58,20\%. Kekuatan tarik menunjukkan peningkatan ke 1,27-6,90 MPa dan perpanjangan menurun menjadi 79,71-46,98\%. Dan untuk permeabilitas edible film berkurang menjadi $12,40-$ 9,97 (g/jam m2).

Kata kunci: Chitosan, Edible film, Tepung Ubi Jalar

\section{PENDAHULUAN}

Pengemasan merupakan suatu kegiatan yang dilakukan guna membatasi kontak suatu produk dengan lingkungan sekelilingnya yang dapat menyebabkan kerusakan pada produk. Pada suatu bahan pangan yang segar, kandungan nutrisinya dapat digunakan oleh mikroorganisme untuk berkembang. Oleh karena itu, apabila tidak ditangani lebih lanjut dapat menyebabkan kerusakan pada produk (Buckle et al., 1987). Edible film merupakan suatu lembar tipis yang dapat dimakan dimana berguna sebagai barrier pada produk pangan dalam mengurangi transfer uap air dan oksigen. Selain itu edible film juga dapat berguna sebagai carrier untuk penambahan zat adiktif pada produk pangan. 
Edible film tidak menyebabkan toksik sehingga aman untuk dikonsumsi (Milda dan Kerry, 2009; Korcha dan Johnson, 1987).

Ubi jalar ungu merupakan salah satu varietas dari ubi jalar di Indonesia. Persebarannya di Indonesia diperkirakan pada tahun 1960-an. Asal tanaman ubi jalar ini dari Selandia Baru, Polinesia dan Amerika bagian tengah. Pada abad ke-16 orang orang spanyol menyebarkan ubi jalar ke kawasan Asia, terutama Filipina, Jepang dan Indonesia (Ginting et al., 2011). Jumlah produksinya belum diketahui tiap tahunnya pada setiap varietas. Namun, produksinya diikutsertakan dalam perhitungan produksi ubi jalar. Produksi ubi jalar pada tahun 2015 tercatat 2.297.364 ton (Badan Pusat Statistik, 2016). Pemanfaatan bahan baku lokal seperti Ubi jalar ungu sebagai bahan baku edible film telah dilakukan oleh Liona (2016).

Pada penelitian sebelumnya dengan menggunakan bahan baku pati ubi jalar ungu (Liona, 2016) dengan menggunakan plasticizer gliserol, edible film yang dihasilkan memiliki karakteristik ketebalan 0,14-0,44 $\mathrm{mm}$ dengan nilai kuat tarik $0,681,68 \quad \mathrm{Kgf} / \mathrm{mm}^{2}$; pemanjangan $6,74-22,14 \%$, kelarutannya $8,67-42,19 \%$ dan masih memiliki antioksidan sebesar 45,57\%. Namun, edible film dengan bahan baku ini masih memiliki nilai karakteristik yang lebih redah dibandingkan dengan film komersial seperti LDPE (Low Density Packaging Etylen) dan HDPE (High Density Packaging Etylen) yang memiliki nilai kuat tarik 16,2 $\mathrm{MPa}$ dan $27,8 \mathrm{MPa}$ serta pemanjangannya $68,7 \%$ dan $150,0 \%$. Selain itu, edible film ini mudah patah walaupun strukturnya kuat dan tidak mudah hancur.

Untuk memperbaiki nilai karakteristiknya yang masih rendah, perlu ditambahkan bahan lain guna menaikkan nilai karakteristiknya agar edible film dapat diaplikasikan lebih luas.

\section{METODE PENELITIAN}

Bahan

Ubi jalar ungu yang digunakan diperoleh dari pasar Tawangmangu, Karanganyar. Ubi jalar ungu yang digunakan memiliki berat minimal 300 gram. Pati ubi jalar ungu didapat dari ekstraksi pati dengan metode basah. Bahan edible film menggunakan pati ubi jalar ungu, plasticizer berupa gliserol, aquades, dan asam asetat glasial cair. Setiap edible film terdiri dari 4 gram pati ubi jalar ungu, $0,8 \mathrm{ml}$ gliserol $(20 \% \mathrm{v} / \mathrm{b})$, aquades dan variasi penambahan kitosan yaitu 0,5 gram; 1,0 gram; dan 1,5 gram.

\section{Alat}

Alat yang digunakan pada penelitian ini berupa beaker glass, gelas ukur, propipet, pipet volume, spatula, magnetic stirrer, hot plate, thermometer, nampan ukuran $16 \times 24$ $\mathrm{cm}$, cabinet dryer, cawan uji laju transmisi uap air, mesin pengayakan, ayakan ukuran 80 mesh, kain saring, timbangan analitik, stopwatch. Micrometer Krisbow 0,01 mm, dan ZWICKI I 0,5 (Universal Testing Machine).

\section{Tahapan Penelitian}

\section{Ekstraksi Pati Ubi Jalar Ungu}

Ubi jalar ungu dibersihkan dari kotoran serta kulit luarnya sehingga yang tertinggal hanya daging ubi jalar ungu. Ubi jalar ungu dipotong kecil disesuaikan dengan ukuran input mesin pemarut. Kemudian hasil pemarutan ditambahkan dengan air dengan perbandingan 1:1. Hasil pemarutan disaring secara manual, kemudian dilanjutkan menggunakan mesin press untuk mengambil filtrat secara maksimal. Filtrat kemudian diendapkan selama 4 jam. Hasil pengendapan yang dapatkan berupa pati basah akan dipisahkan dari air. Pati basah yang didapatkan dikeringkan dengan suhu $50^{\circ} \mathrm{C}$ selama 24 jam. Pati kering yang didapatkan diayak menggunakan ayakan ukuran 80 mesh. Kemudian dilanjutkan perhitungan randemen dari pati ubi jalar ungu.

\section{Pembuatan Edible Film}

4 gram pati ubi jalar ungu dilarutkan dalam $50 \mathrm{ml}$ aquades dan diaduk hingga homogen. Larutan pati kemudian dipanaskan hingga suhu $70^{\circ} \mathrm{C}$ kemudian ditambahkan gliserol 20\% v/b dan diaduk hingga homogen sehingga terbentuk larutan pati. Kitosan sebanyak 0,5 gram; 1,0 gram dan 1,5 gram ditimbang kemudian dilarutkan dalam $50 \mathrm{ml}$ asam asetat $1 \%$ dan diaduk pada suhu $50^{\circ} \mathrm{C}$ hingga homogen sehingga terbentuk larutan kitosan. Larutan pati dan larutan kitosan 
dicampur dan diaduk pada suhu $95^{\circ} \mathrm{C}$ selama 15 menit hingga homogen. Kemudian larutan edible dicetak dalam nampan edible film dan dioven selama 24 jam pada suhu $50^{\circ} \mathrm{C}$ sehingga terbentuklah edible film pati ubi jalar ungu dengan penambahan kitosan.

\section{HASIL DAN PEMBAHASAN}

Penelitian ini menggunakan perbedaan jumlah kitosan (0,5 gram; 1,0 gram dan 1,5 gram) yang digunakan dalam pembuatan edible film pati ubi jalar ungu. Edible film kemudian disimpan selama 2 hari untuk selanjutnya diuji karakteristik fisik (ketebalan, kelarutan dan laju transmisi uap air) dan mekanik (kuat tarik dan pemanjangan).

\section{Ketebalan}

Ketebalan film merupakan salah satu aspek penting dalam menentukan kemampuan edible film dalam mencegah terjadinya pertukaran zat dari lingkungan atau sebaliknya terutama pada aplikasinya menggunakan metode coating (Gutierrez et al., 2014). Ketebalan edible film yang dihasilkan berkisar $0,10 \mathrm{~mm}-0,19 \mathrm{~mm}$. Ketebalan edible film terendah didapatkan pada penambahan 0 gram kitosan dan ketebalan tertinggi didapatkan pada penambahan 1,5 gram kitosan. Gambar 1 menunjukkan penambahan kitosan dalam pembuatan edible film berbahan pati ubi jalar ungu cenderung menaikkan ketebalan. Guntarti et al. (2015) menjelaskan penambahan kitosan akan meningkatkan total padatan dan polimer penyusun edible film. Semakin tinggi kitosan yang ditambahkan maka viskositas larutan edible film juga semakin tinggi yang akan membentuk edible film yang semakin tebal.

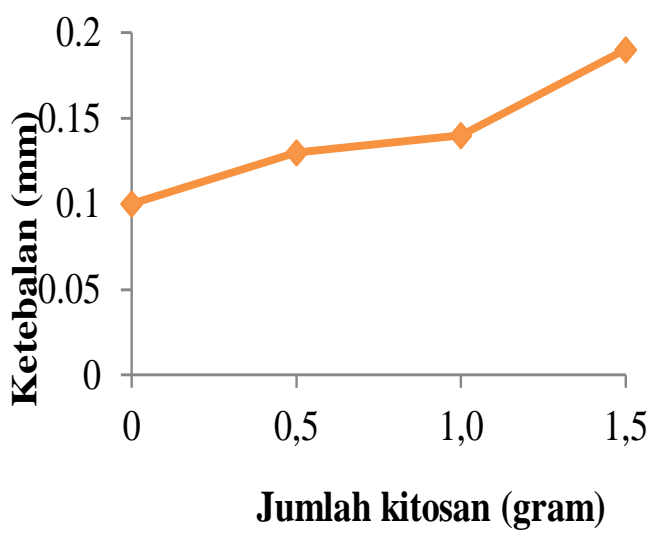

Gambar 1 Pengaruh Penambahan Kitosan terhadap Ketebalan Edible film

\section{Kelarutan}

Kelarutan edible film yang dihasilkan berkisar 58,20 \%-68,00 \%. Dengan nilai terendah pada penambahan 1,5 gram kitosan dan nilai tertinggi pada penambahan 0 gram kitosan. Gambar 2 menunjukkan bahwa penambahan kitosan cenderung menurunkan nilai kelarutan edible film yang terbentuk. Hal ini dijelaskan oleh Darajat et al. (2015) bahwa jumlah kitosan yang ditambahkan akan mempengaruhi jumlah komponen terlarut dalam larutan edible menjadi lebih banyak. Jumlah komponen terlarut ini akan berpengaruh terhadap nilai kelarutan edible film. Semakin tinggi komponen terlarutnya maka kelarutannya akan semakin rendah.

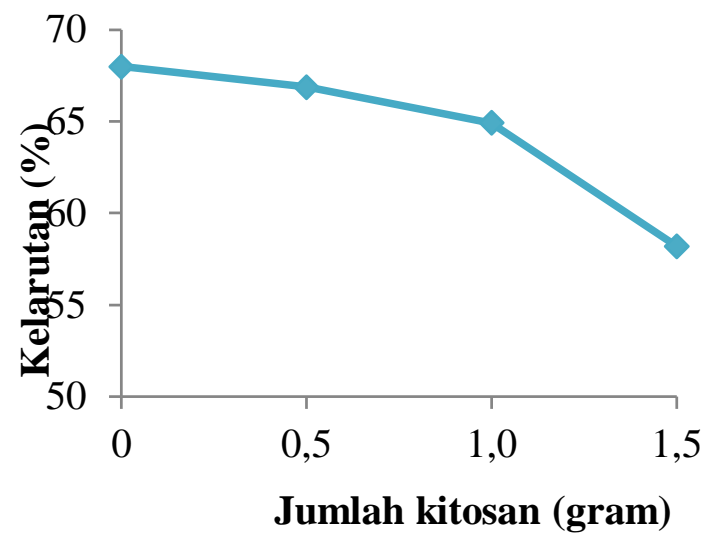

Gambar 2 Pengaruh Penambahan Konsentrasi Kitosan terhadap Kelarutan Edible film

\section{Laju Transmisi Uap Air}

Ghanbarzadeh et al. (2011) menjelaskan bahwa dalam pengaplikasian edible film sebagai pengemas, dibutuhkan 
nilai laju transmisi uap air serendah mungkin agar dapat menjaga kualitas bahan pangan yang akan dilapisi oleh edible film. nilai laju transmisi uap air berkisar 9,97 (g/jam $\left.\mathrm{m}^{2}\right)$ 13,11 (g/jam $\left.\mathrm{m}^{2}\right)$. Nilai tertinggi laju transmisi uap air didapatkan pada penambahan 0 gram kitosan sebesar 13,11 $\left(\mathrm{g} / \mathrm{jam} \mathrm{m}^{2}\right)$. Sedangkan untuk laju transmisi uap air terendah pada penambahan 1,5 gram kitosan sebesar 9,97 (g/jam m²). Gambar 3 menunjukkan penambahan kitosan dalam edible film dari pati ubi jalar ungu cenderung menurunkan nilai laju transmisi uap airnya. Darajat et al. (2015) menjelaskan bahwa penambahan kitosan akan meningkatkan jumlah komponen terlarut menjadi lebih banyak. Sehingga edible film yang terbentuk akan memiliki kerapatan film yang semakin tinggi. Kerapatan film ini akan menghambat transmisi uap air sehingga uap air tidak mudah melewati edible film.

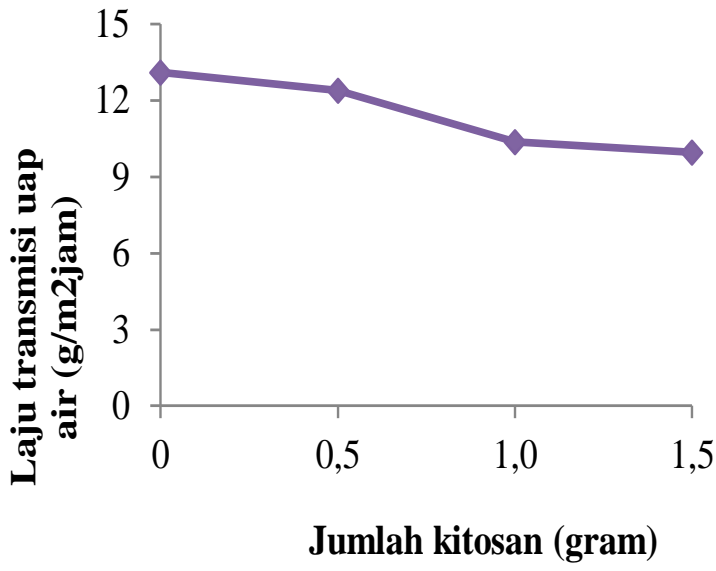

Gambar 3 Pengaruh Penambahan kitosan terhadap Laju Transmisi Uap Air Edible film

\section{Kuat Tarik}

Korchta dan Johnson (1997) menjelaskan kuat tarik atau tensile strength merupakan gaya maksimum yang dapat ditahan oleh edible film sebelum putus. nilai kuat tarik yang dihasilkan sebesar $0,67 \mathrm{MPa}-$ 6,90 $\mathrm{MPa}$. Nilai kuat tarik terendah pada penambahan 0 gram kitosan sebesar 0,67 $\mathrm{MPa}$ dan nilai kuat tarik tertinggi pada penambahan 1,5 gram kitosan sebesar 6,90 MPa. Gambar 4 menunjukkan penambahan kitosan dalam edible film dari pati ubi jalar ungu cenderung menaikkan nilai kuat tariknya. Xu et al. (2005) menjelaskan peningkatan nilai tensile strength dikarenakan terbentuknya ikatan hidrogen inter-molekuler antara $\mathrm{NH} 3+$ pada kitosan dengan $\mathrm{OH}$ - pada pati. Amino $(\mathrm{NH} 2)$ pada kitosan bereaksi pada pelarut asam sehingga membentuk NH3+ yang berkontribusi pada pembentukan film. Pada proses gelatinisasi pati, ikatan $\mathrm{OH}$ yang terpisah dengan mudah berikatan dengan $\mathrm{NH} 3+$ dari kitosan. Sehingga jumlah ikatan hidroksil akan meningkat seiring dengan pembentukkan film.

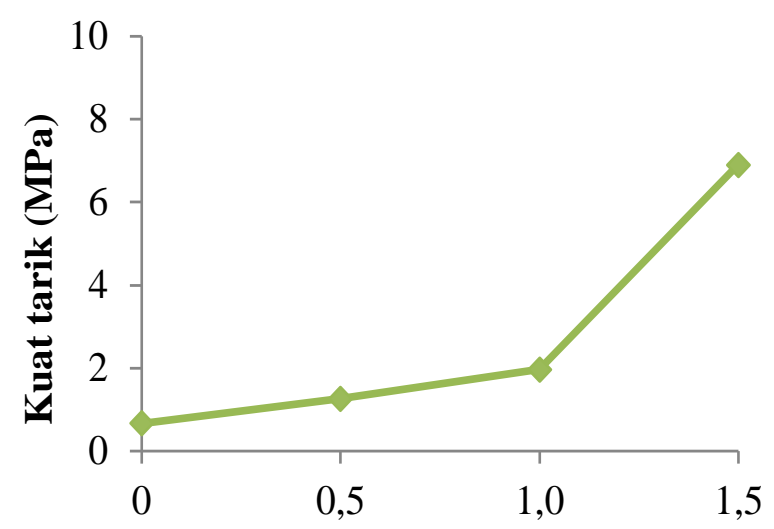

Jumlah kitosan (gram)

Gambar 4 Pengaruh Penambahan Kitosan terhadap Kuat Tarik Edible film

\section{Pemanjangan}

Korchta dan Johnson

menjelaskan pemanjangan atau elongation merupakan persen $(\%)$ peregangan maksimal suatu edible film sebelum putus. Nilai pemanjangan edible film dari pati ubi jalar ungu dengan penambahan kitosan sebesar $46,98 \%-130,54 \%$. Nilai pemanjangan tertinggi pada penambahan 0 gram kitosan dengan nilai $130,54 \%$ dan pemanjangan terendah pada penambahan 1,5 gram kitosan dengan nilai $46,98 \%$. Gambar 5 menunjukkan penambahan kitosan cenderung menurunkan pemanjangan edible film berbahan baku pati ubi jalar ungu. Darajat et al. (2015) menjelaskan bahwa penambahan kitosan akan meningkatkan kuat tarik namun menurunkan nilai elongasi. Hal ini dikarenakan, penambahan jumlah kitosan akan membentuk edible film yang lebih tebal, dimana jumlah komponen terlarut menjadi lebih banyak. Sehingga film yang terbentuk memiliki karakteristik yang kaku dan memiliki kerapatan film yang semakin tinggi. 
Hal inilah yang akan menurunkan elastisitas suatu film. Xu et al. (2005) menjelaskan lebih lanjut bahwa ikatan hidrogen yang terbentuk antara kitosan dengan amilosa dan amilopektin menghasilkan edible film yang kuat sehingga kemampuan elastisitasnya menurun. Semakin banyak kitosan yang ditambahkan akan menghasilkan ikatan hidrogen yang semakin banyak pula sehingga akan menurunkan elastisitas edible film tersebut.

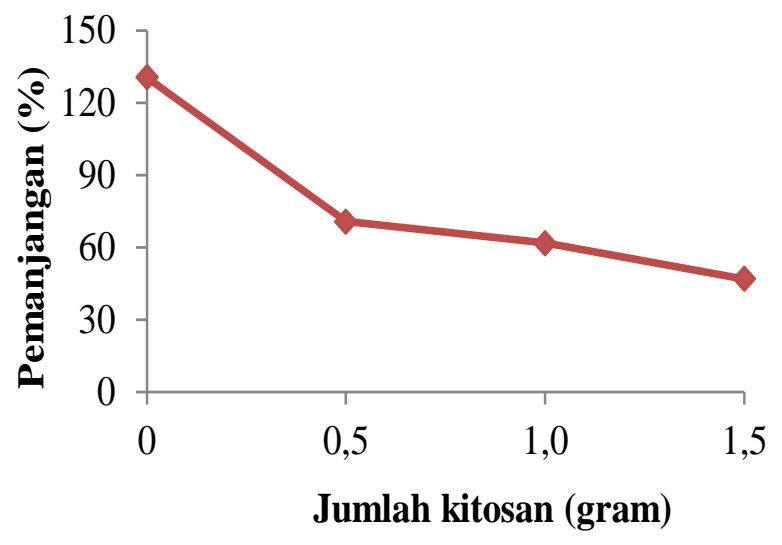

Gambar 5 Pengaruh Konsentrasi Penambahan Kitosan terhadap Pemanjangan Edible film

\section{KESIMPULAN DAN SARAN}

\section{Kesimpulan}

Penambahan kitosan akan menaikkan ketebalan film dan kuat tarik, namun menurunkan kelarutan, pemanjangan dan nilai laju transmisi uap air dari edible film yang terbentuk.

\section{Saran}

Perlu dikaji lebih lanjut tentang pemanfaatan edible film tersebut dalam mempertahankan kualitas bahan pangan selama penyimpanan.

\section{DAFTAR PUSTAKA}

. 1997. Official Methods of Analysis. Association of Official Analytycal Chemits Inc.

Akpa, Jackson G, dan K. K. Dagde. 2012.Modification of Cassava Starch for Industrial Uses. International Journal of Engineering and Technology Volume 2 No.6, Juni, 2012.
Association of Official Analitycal Chemists [AOAC]. 1995. Official Methods of Analysis. Association of Official Analytycal Chemits Inc.

Badan Standarisasi Nasional. 2009. SNI3751-2009: Syarat Tepung sebagai Bahan Baku Makanan.

Badan Pusat Statistika. 2016. Produksi Ubi Jalar Menurut Provinsi 2011-2015. http://bps.go.id diakses 13 April 2017.

Bhuvaneshwari, S., D. Sruthi, V. Sivasubramanian, Niranjana K., dan J. Sugunabai. 2010. Development and characterization of chitosan film. International Journal of Engineering Research and Applications (IJERA). ISSN: 2248-9622. Vol. 1, Issue 2, pp.292-299.

Bourtoom, T. 2008. Edible film $s$ and coatings: characteristics and properties. International Food Research Journal 15(3): 237-248

Buckle, K. A., Edwards R. A., Fleet G. H., dan Wootton M. 1987. Ilmu Pangan. Departemen Pendidikan dan Kebudayaan Direktoral Jendral Pendidikan Perguruan Tinggi Proram Internasional Universitas Australia. UIPress:Jakarta.

Dallan P.R., Pattricia da L.M., Petinari L., Maria S.M., Masumi M.B., Candelara S. G., dan Maria, A.M. 2006. Effect of Chitosan Solution Concentration and Incorporation of Chitin and Glycerol on Dense Chitosan Membrane Properties. Journal of Biomedical Research. Wiley InterScience Inc.

Darajat Z. N., Gede S. M., Sri S., dan Endang S., 2015. Karakterisasi dan Sifat Biodegradasi Edible Film dari Pati Kulit Pisang 'Nangka (Musa Paradisiaca L.) dengan Penambahan Kitosan dan Plasticizer Gliserol. Prosiding Seminar Nasional Teknik Kimia. ISSN 1693-4393.

Elshabee, Maher Z, dan Entsaar S. Abdou. 2013. Chitosan based edible film $s$ and coatings. Journal Elsevier: Material Science and Engineering C.

Garcia, N.L., L. Ribbon, A. Dufresne, M. Aranguren, and S. Goyanes. 2011. Effect of glycerol on the morphology of 
nanocomposites made from thermoplastic starch and starch nanocrystals. Carbohydrate Polymers 84(1): 203-210.

Gede, I. S. M. H dan Puspita T., 2011. Pengaruh Penambahan Khitosan dan Plasticizer Gliseropada Karakteristik Plastik Biodegradable dari Pati Limbah Kulit Singkong.

Ghanbarzadeh, B., Almasi, H., dan Entezami, A. A. 2011. Improving the Barrier and Mechanical Properties of Corn Starch-Based Edible films: Effect of Citric Acid and Carboxymethyl Cellulose. Industrial Crops and Products.

Ginting, E., Joko S., Utomo, Rahmi Yulianti, dan M. Jusuf. 2011. Potensi Ubijalar Ungu sebagai Pangan Fungsional. Iptek Tanaman Pangan.

Gontard, N., Stephnie G., dan Jean-Louis Cuq. 1993. Water And Glyserol as Plasticizer Affect Mechanical And Water Barrier Properties At An Edible Wheat Gluten Film. Journal Food Science.

Gutierrez, T. J. María S. T., Elevina P., dan Lucía F.. 2015. Structural and Mechanical Properties of Edible films Made from Native and Modified Cushcush Yam and Cassava Starch. Food Hydrocolloids 45 (2015)

Guntarti, S., Agustina A. C., dan Anna F. 2015. Karakterisasi Sifat Fisik dan Mekanik Penambahan Kitosan pada Edible Film Karagenan dan Tapioca Termodifikasi.

Han J. H., Seo G. H., Park I. M., Kim G. N., Lee D. S. 2006. Physical and mechanical properties of pea starch edible films containing beeswax emulsions. Journal of Food Science.

Hidayah, I. B., N. Damajanti, dan Endar P. 2015. Pembuatan Biodegradable Film dari Pati Biji Nangka (Artocarpus hetrophyllus) dengan Penambahan Kitosan.. UPN Veteran Yogyakarta.

Ji, H., H. Zhang, H. Li, dan Y. Li. 2005. Analysis of the Nutrition Composition and antioxidant Activity of Different Types of Sweet Potato Cultivars. Food and Nutrition Science.
Joana F. M. A. C., Quintas, Cristina L. M., dan Silva. 2009. Influence of film forming solutions on properties of chitosan/glycerol films. Fundacão para a Ciência e aTecnologia.

Katili S., Bayu Tri Harsunu dan Suryo Irawan, 2013. Pengaruh Konsentrasi Plasticizer Gliserol dan Komposisi Khitosan dalam Zat Pelarut terhadap Sifat Fisik Edible Film dari Khitosan.

Krochta, J. M., and C. M. Johnson. 1997. Edible film and Biodegradable Polymer Film Challenger and Opportunities. Food Tech, 51 ( 2 ); 6174.

Liona, R. 2016. Studi Pembuatan Edible film dari Pati Ubi Jalar Ungu (Ipomea batatas L. poir) sebagai Kemasan Pada Dodol. Skripsi Jurusan Teknologi Hasil Pertanian Universitas Syiah Kuala.

Matsui, K. N., Lorotonda, F. D. S., Pacs, S. S., Luiz, D.B., Pires, A. T. N., dan Laurindo, J. B. 2004. Cassava bagassekraft paper composite; analysis of influence of impregnation with starch acetate on tensile strength and water absorption properties. Carbohydrate Polymers.

McHugh, T. Habig., R. Avena-Bustillos, dan J.M. Krochta. 1994. Hydrophilic Edible films : Modified Procedure for Water Vapor Permeability and Eksplanation of Thickness Effects. Journal of Food Science, Vol. 58, No.4

Milda, E. and Kerry C., 2009. Edible film s and Coatings for Food Applications. Springer.

Nurhayati, dan Agusman. 2011. Edible film Kitosan darib Limbah Udang sebagai Pengemas Pangan Ramah Lingkungan. Balai Besar Riset Pengolahan Produk dan Bioteknologi Kelautan dan Perikanan. Vol. 6, No. 1

Onwueme, I.C. 1978. The Tropical Tuber Crops. John Wiley and Sons Ltd. New York.

Peressini, D., Bravin B., Lapasin R., Rizzotti C., dan Sensidoni A. 2003. Starchmethylcellulose based edible films: rheological properties of film-forming 
dispersions. Journal of Food Engineering.

Skurtys O., Acevedo C., Pedreschi F., Enrione J., Osorio F., dan Aguilera J. M. 2010. Food Hydrocolloid Edible Film and Coating. Department of Food Science and Technology, University de Santiago de Chile.

Smith, S.A. 1986. Polyethylene, low density . In : Edible films and coating for food applications by Milda E and Kery. Springer.

Sudirman, M. A. 2012. Karakteristik Edible film dari Pektin Hasil Ekstraksi Kulit Pisang. Jurnal Keteknikan Pertanian. Vol. 26, No. 1

Syarifudin A. dan Yuniarta, 2015. Characterization of Edible film from Grapefruit Albedo Pectin and Arrowroot Starch. Jurnal Pangan dan Agroindustri Vol. 3 No 4

Tina L. dan T. Liu, 2008. Edible Films from Starch and Chitosan:Formulation and Gas Permeabilities.

Utama, I M. S. dan Nyoman S. Antara. 2013. Pasca Panen Tanaman Tropika: Buah dan Sayur. Tropical Plant Curriculum Project. Udayana University. Denpasar.

Vroman, I. dan T. Lan. 2009. Biodegradable Polymers. Materials 2009, 2, 307-344.

Winarti, C., Miskiyah, \& Widaningrum. 2012. Teknologi Produksi dan Aplikasi Pengemas Edible Antimikroba Berbasis Pati. TeknJ. 31(3): 85-93

Woofle, J. A. 1992. Sweet Potato an untappaped food resource. Cambridge University Press.

Xu. Y.X, Kim M.A dan D. Nag. 2005. Chitosan-starch composite film: preparation and characterization. Journal Industrial crops and product. Elsevier.

Yusmarlela. 2009. Studi Pemanfaatan plastisiser Gliserol dalam Film Pati Ubi dengan Pengisi Serbuk Batang Ubi Kayu. Universitas Sumatera Utara, Medan. 